\title{
EL COMPONENTE ERÓTICO EN LA REESCRITURA DE LA CONQUISTA Y EL DESCUBRIMIENTO DE AMÉRICA EN DAIMÓN DE ABEL POSSE
}

The erotic element in the rewriting of the conquest and discovery of America in Abel Posse's Daimón

\author{
CHRISTIAN RENÉ RIVERA R. \\ Universidad de Salamanca (España) \\ riverdell22@hotmail.com
}

Resumen

El presente estudio tiene como finalidad el análisis e interpretación del componente erótico en la novela Daimón. Bajo este presupuesto teórico, se promueve un enfoque contradiscursivo en el que América es transfigurada en espacio erótico, donde el tiempo pagano se superpone a la temporalidad oficial, desatando una crítica continua que desafía lo que se considera como la verdad oficial de los hechos.

Palabras clave: Erotismo; historia oficial; contradiscurso; conquista de América.

Abstract

The article is an analysis and interpretation of the erotic element in the novel Daimón. Based on this theoretical premise, it proposes a counter-discursive approach in which America is transfigured in an erotic space in which pagan time overlaps accepted temporality, unleashing a continuous critique that challenges the official truth of historical events.

Key words: Eroticism; official history; counter-discourse; conquest of America.

\section{INTRODUCCIÓN}

El 12 de octubre de 1492, el encuentro de dos culturas, diametralmente disímiles, trajo como consecuencia la imposición de un discurso histórico hegemónico. Este discurso, tomado como Historia Oficial, es en esencia una manifestación discursiva parcializada y discriminatoria, en la que se enmascara un proceso sistemático de anulación de la memoria social de las civilizaciones sometidas. Ante la cuasidestrucción de su memoria ontológica y cultural, América Latina encuentra en su literatura (y en muchas otras manifestaciones culturales) los elementos que permitan articular muchos segmentos dispersos alojados en su memoria para luego ser asumidos mediante alusiones literarias.

En el caso que nos ocupa, la novela Daimón (1978) del escritor argentino Abel Posse rescata la figura de Lope de Aguirre, personaje repudiado por la historia oficial, quien, junto con sus marañones, se levanta de entre los muertos para continuar la búsqueda de El Dorado y refrendar de esta manera su rebeldía contra la Corona española: "Desde un primer momento, el alzamiento de Lope de Aguirre es en sí mismo una afrenta 
al propio rey. De hecho, en su rechazo y desprecio de la autoridad real, Aguirre va construyendo también la imagen de su poder, que podríamos considerar como un contrapoder" (Diez, 2018, p. 195)

En efecto, Aguirre ha sido un asunto incómodo para la Historia Oficial, debido a que su levantamiento contra la Corona lo puso en el lado opuesto de los valores civilizatorios de Occidente. De modo que un personaje tan marcadamente opuesto, no solo le da la espalda a la Corona española, sino que, además, asumiendo ese contrapoder, plantea problematizar la historia tal como la hemos conocido.

[...] Y esta frase, anótala bien: Excelentísimo Señor, me dispongo a una larga jornada de América. Voy con mis verdugos y mis víctimas por estas tierras fantásticas. Vuelvo a firmar esta carta con mi título de traidor, que no es fácil de conquistar. Porque debo traicionaros para poder ser el Rebelde (así con mayúscula) (Posse, 1989, pp. 22- 23).

Sabemos que toda vinculación con el pasado es emotiva y que todo testimonio se revela esclavo de perspectivas individuales, porque se apoya en la memoria, las circunstancias y las pasiones. Esto explica el por qué un mismo suceso se resiste a ser narrado de idéntica manera por dos personas distintas. Hyden White (2003) sostiene que, para ser narrado, todo suceso ha de ser articulado mediante figuras retóricas. Son estos elementos tropológico-literarios los que permiten iluminar los hechos y darles una figuración documental. Por consiguiente, es evidente que, en las Crónicas y Cartas de Relación acerca del Descubrimiento y la Conquista de América, la frontera entre historia y artificio literario es de manera constante permeada.

Como destaca Sosnowski (2010), "Proponerse la invención de una novela total para re-escribir la historia que se siente y se sabe propia implica aceptar que el territorio nacional es central y que corresponde dejar de asumirlo como periferia frente a otras latitudes" (p. 760). Es esta aspiración por forjar una historia propia, posmoderna, descolonizada y multicultural la que ha desplegado, en la Nueva Novela Histórica Latinoamericana, una proliferación "ilegítima" y "adulterada" de los acontecimientos que permiten una viva confrontación entre la visión unívoca y parcializada de la "historia oficial" y sus "versiones apócrifas". En ese sentido, este escrito intenta reflexionar y descubrir cómo el acontecimiento histórico y su figuración literaria consiguen desacralizar la histórica oficial mediante el componente erótico presente en Daimón.

1. LA REESCRITURA DE LA HISTORIA. PUNTOS DE PARTIDA, BREVES RASGOS DE LA NUEVA NOVELA HISTÓRICA EN HISPANOAMÉRICA

La superposición de la ficción literaria respecto del hecho histórico empieza en la incorporación de los relatos míticos europeos acerca de la realidad de los territorios 
americanos. A falta de términos con los cuales señalar la realidad americana, los conquistadores españoles proceden a llenar estos vacíos semánticos, semióticos y ontológicos mediante concepciones míticas que forjaron la concepción eurocéntrica del mundo, dando como resultado la superposición de un relato ajeno a la realidad. La conquista española, en su afán de borrar todo vestigio de memoria en las culturas precolombinas, sometieron a las civilizaciones americanas a una desestructuración de la memoria mediante relatos y crónicas ilegítimas y adulteradas, trayendo consigo, el reemplazo de un pasado y la adopción forzada de un calendario ajeno como extraño.

Seymour Menton señala que la novela histórica tradicional se remonta a inicios del siglo XIX y se halla muy relacionada al movimiento romántico. No obstante, en Latinoamérica, la novela histórica tradicional se encuentra influenciada por el teatro del Siglo de Oro y por las crónicas coloniales. Este tipo de novela histórica dará origen a la novela nacional (Menton, 1993).

Durante el transcurso del siglo XIX, la formación de las nuevas naciones hispanoamericanas exigía una revisión histórica en contraposición al pasado colonial con el fin de legitimar las guerras de independencia. Las nuevas naciones americanas enfrentaban el futuro con una carencia de pasado o al menos con grandes lagunas históricas en sus orígenes. Dentro de este marco, la novela histórica de corte romántico se iba ajustando a las exigencias y necesidades que demandaban las circunstancias de las jóvenes naciones latinoamericanas.

Durante la primera mitad del siglo XX, la influencia del naturalismo positivista, el realismo y sus variantes ejercerán autoridad científica sobre la novela histórica y le exigirán una sustentación documental lo más apegada a los acontecimientos y a los postulados del nuevo pensamiento moderno. En cierto sentido, la influencia del realismo y la muy particular adaptación de la pintura de costumbres en la novela hispanoamericana vuelve inútil una diferenciación de estos movimientos; durante este periodo convergen una pluralidad de propuestas y alternativas que como lo observa María Beatriz Aracil (2004)

diversos autores señalan un debilitamiento en el desarrollo del género durante la primera mitad el siglo XX (con la excepción de Uslar Pietri, que inicia su trayectoria en la década de los 30, y de Carpentier, desde los 40) que obedece a motivos ideológicos, pero también a motivos literarios muy especialmente a la aparición en Latinoamérica de la "nueva novela" que comienza a definirse en los años 40 , confirmándose con el boom de los años 60 (Aracil, p. 60).

Esta nueva visión, a la que puede señalarse como el origen de la Nueva Novela Histórica escrita en territorio hispanoamericano, empieza a perfilarse desde la publicación de El reino de este mundo (1949) del escritor cubano Alejo Carpentier. A la 
novela anterior, le seguirán, El siglo de las luces ${ }^{1}$ (1962) y El arpa y la sombra (1979). Este mismo empeño se percibe en otros escritores, ese es el caso de Augusto Roa Bastos con Yo el supremo (1974). Así también en dos novelas escritas por Gabriel García Márquez: El otoño del patriarca (1975), novela a la que le seguirá El General en su Laberinto (1989). Este mismo año Carlos Fuentes publica Terra Nostra (1975). Bajo esta misma línea argumental debemos hacer mención de las novelas: Noticias del Imperio (1989) de Fernando del Paso; La guerra del fin del mundo (1981) o La Fiesta del Chivo (2000) de Mario Vargas Llosa. Así como también: la trilogía del descubrimiento y la conquista de Abel Posse (1978 a 1992), entre las más importantes.

En relación con lo anotado, conviene recordar que la novela histórica latinoamericana, desde la última mitad de siglo XX, sufre innovaciones narrativas a partir de las propuestas formuladas por el boom latinoamericano, donde se puede observar una preocupación en favor de las dimensiones míticas del espacio y el tiempo. Esta nueva forma de novelar la historia deja a un lado la temporalidad oficial y permite al imaginario latinoamericano recuperar una cosmovisión mítica por medio de un lenguaje reelaborado que le permita descubrir una realidad silenciada por el lenguaje jerarquizado del discurso eurocéntrico que forjó la historia oficial.

Esta actitud estética adopta una posición de rechazo a los procedimientos literarios llevados a cabo por el realismo de corte criollista y regionalista, originados en un pensamiento burgués y que a partir del boom fueron cuestionados por fijar estereotipos originados en la dicotomía civilización y barbarie. En contraste, esta generación de novelistas adoptó nuevas técnicas narrativas provenientes de la literatura universal (Faulkner, Dos Passos, Mann, Joyce, entre otros), pero además abordan el carácter trágico de la condición humana a partir de los presupuestos del surrealismo, el existencialismo y el psicoanálisis que les permiten explorar la subjetividad del mito en contraste con la cultura de la modernidad.

Es indispensable, entonces, resumir los rasgos distintivos que la Nueva Novela Histórica exhibe a partir de la segunda mitad del siglo XX. El primero en registrar estas características fue Seymour Menton, quien en 1972 publica, en su libro La nueva novela histórica de América Latina, varias tipologías narrativas que distinguen a la nueva novela histórica practicada en América Latina. Así, vemos que Menton distingue los siguientes rasgos:

1) Una subordinación de la presentación del periodo histórico a planteamientos filosóficos de la historia y el tiempo sugeridos en los cuentos borgeanos.

\footnotetext{
${ }^{1}$ La importancia de El Siglo de las luces consiste en que plantea de forma explícita el problema de la Historia en América Latina de los negros esclavos en América que tenían su propia versión de la Historia. Esta novela de Carpentier presenta la constante inversión distorsión con que los ecos de la revolución francesa llegan a América Latina (Pons, 1996, p. 103).

156 | AlpHA № 53 (Diciembre 2021) PÁGS. 153-167. ISSN 07 16-4254
} 
2) Distorsión de la historia mediante omisiones, exageraciones y anacronismos.

3) Ficcionalización de personajes históricos destacados. Plantea como protagonistas a personajes de relevancia histórica, con el propósito de desmitificar su figura legendaria.

4) Metaficción o comentarios críticos del narrador del proceso de creación.

5) Intertextualidad.

6) La carnavalización del texto histórico.

De los rasgos destacados por Menton, este trabajo se centra en el componente erótico que, como se irá descubriendo a lo largo de estas páginas, es asumido como una categoría de lo grotesco, incluida por Mijail Bajtin dentro del carnaval.

\section{EL CARNAVAL BAJTINIANO Y SU ARTICULACIÓN CON LO ERÓTICO}

El carnaval es presentado por Bajtin como un espacio festivo de carácter popular y colectivo, donde los valores construidos bajo una estructura social jerarquizada se invierten. Esta esfera de desorden es una invitación a transgredir los límites no solo de la conducta, sino también de los discursos sociales; en definitiva, rompe los límites de la oficialidad y provoca la confusión de los valores contrapuestos.

El procedimiento de carnavalización refleja un deseo de subvertir el orden, una clara intención de invertir las jerarquías y proyectar un discurso desde la periferia. Esto tiene como propósito confrontar una doble tradición: la central y la marginal (en el caso de Daimón: la del conquistador y la del conquistado). En este sentido, el componente erótico se articula al carnaval bajtiniano por medio de lo grotesco (la exageración sexual, la glotonería, así como el énfasis en las funciones corporales, entre otros).

Como se ha señalado antes, Daimón exhibe lo grotesco como una categoría del carnaval, la misma que sugiere el rebajamiento de lo elevado, lo espiritual y sublime hacia un plano material y corporal, donde se privilegian imágenes de origen pagano (no oficial) cargadas de una pulsión erótica de tono exuberante, asumida por las culturas precolombinas por medio de los cultos consagrados a la naturaleza, con claras referencias hacia lo femenino (la tumba y el vientre), como se verá más adelante.

\section{EL PANEROTISMO PREHISPÁNICOEN DAIMÓNCOMOCATEGORÍA DELO GROTESCO}

Mijail Bajtin concibe lo grotesco como La rehabilitación de la carne. En efecto, el realismo grotesco tiene como principio fundamental el vínculo del individuo con la totalidad viviente del universo, porque supone al hombre como un elemento inherente al 
reino de la naturaleza que se encuentra ligado a la totalidad planetaria ${ }^{2}$. En tal sentido, es importante resaltar que las culturas prehispánicas percibían al ser humano como una emanación natural del entorno, lo que aclara la relación de identidad que estas civilizaciones mantenían con la naturaleza y, como lo afirma el narrador de Daimón, "No solo los hombres de los pueblos selváticos sino también las plantas y los animales, pronto quedaron convencidos de que estos invasores estaban profundamente enemistados con el Espíritu de la Tierra" (Posee, 1989, p. 43).

Por otra parte, la concepción de las culturas prehispánicas se cumple en el principio de lo que Bajtin describe como la fiesta utópica. Es ese estado en que lo cósmico, lo social y lo corporal permanecen ligados de manera indisoluble en una totalidad viviente e indivisible. Esta concepción estética, en Daimón, va a ser privilegiada con imágenes de la vida corporal como lo son la fertilidad, el crecimiento y la exuberancia ${ }^{3}$. Así, es posible encontrar en algunos pasajes de la novela un entorno opulento, donde todas las cosas parecen participar del principio multiplicador.

América. Todo es ansia, jugo, sangre, savia, jadeo, sístole y diástole, alimento y estiércol, (...) A los sacrificios y carnicerías sigue el jadeo rítmico de los acoplamientos. Partos, asesinatos, extinciones, cataclismos. Las quietas flores humedecidas de rocío se entreabren durante la noche para parir la semilla de la araucaria gigantesca. Las tigras corren al alba hacia sus crías llevando el venado exánime, chorreando sangre caliente. Los jacarandáes se incitan con el rozamiento de las ramas más altas movidas por la brisa y estallan en nubes de polvo amarillo, fecundador (Posse, 1989, p. 13).

Ahora bien, es necesario puntualizar que la fertilidad del entorno se presenta en Daimón como una vinculación de lo material y lo corporal al Todo universal; a lo que se añade otro rasgo sobresaliente del realismo grotesco, la degradación mediante la transferencia de lo "elevado" a lo terrenal. Y es justamente dentro de esta concepción desacralizadora que se inserta la tendencia a lo erótico, ya que, al estar tan vinculados a la fertilidad de la tierra, el ser humano también participa de la voluptuosa lascivia que sufre el entorno.

En una noche de luna, cuando ya habían superado el diluvio y marchaban por unas tierras secas y rojas que el Cura ubicó como cercanas al primer círculo infernal, escucharon un estrépito que sacudía y hacía vibrar los troncos afincados quebrados como si fueran juntos movidos por la brisa.

\footnotetext{
2 De hecho, la "naturaleza" es todo de la "realidad", y no una entidad opuesta a otra (como "culturalidad" o "espiritualidad"). Es significativo que no exista ningún vocablo quechua para "naturaleza" (Estermann, 2015, p. 188).

${ }^{3}$ La pachamama (madre tierra) cumple, en cierto sentido, una función simbólica similar a la coca: "relaciona" los tres estados del universo, por medio de su fecundidad (Estermann, 2015, p. 189).

158 | AlPHA № 53 (DicIEMBre 2021) PÁGS. 153-167. ISSN 07 16-4254
} 
En un claro de la sabana roja descubrieron dos animales de otras eras, dos tatúes o gliptodontes caudados con caparazones en forma de domo y de más de veinte pasos de tamaño. (...)

Descubrieron que el paso de los monstruos respondía a una secreta armonía. El advertido y analítico Lipzia afirmó que se trataba de una danza nupcial que había visto ejecutar a los cangrejos en la playa de Travemünde durante uno de sus exilios forzosos (...) Comprendieron que el resoplido que movía las hojas a cincuenta pasos de distancia respondía a un homérico deseo carnal (Posse, 1989, pp. 34-35).

En efecto, en Daimón encontramos un universo donde se participa de una "comunión sexual" y es tan intenso el sentido de la libido que las prácticas sexuales en las que incurren son poco convencionales desde la perspectiva del mundo occidental. "Las silenciosas expediciones del Cura y del Escribano guiados por el lujurioso Spínola para acoplarse a las sedosas orquídeas contráctiles que los devolverán extenuados al amanecer (...)" (Posse, 1989, p. 36).

De hecho, en la novela se destaca el predominio del principio corporal de la satisfacción de las necesidades naturales y la vida sexual. Cuando Lope descubre los paseos eróticos del cura y el escribano, el narrador manifiesta: "El Viejo se deslizaba entre ellos como no viéndolos. Su experiencia de mando le había enseñado que los vicios de los hombres son indeclinables y que cierta tolerancia impide traslaciones o exposiciones peores" (Posse, 1989, p. 37).

Ahora bien, como se pudo apreciar, América se transforma en la matriz eróticogrotesca donde el componente corporal se vincula con la exuberancia vegetal del entorno y articula el tiempo de vida de los conquistadores al devenir cíclico de las civilizaciones precolombinas. De este modo, el "resurgimiento" de los conquistadores: "Timidones, todavía con pesadez de lápida. Como paridos de vuelta" (Posse, 1989, p.14). Incorpora a su "resurrección" las dos naturalezas: la cósmica y la terrenal. Es justamente esta condición de "redivivos" lo que hace posible una impugnación del devenir histórico occidental. Debido a que la realización de la historia oficial no contempla el retorno, porque implicaría una crítica continua e ilimitada del pasado, con lo que sería impensable una versión oficial.

\section{EROS Y TANATOS: LA REINTEGRACIÓN DE LOS MUERTOS ALDISCURSO HISTÓRICO}

Para empezar, es necesario señalar que no es nada extraño hallar en la figura de Eros una relación directa con la civilización. Ya los griegos aventuraron un razonamiento en esta poderosa pulsión. Más aún, fueron los primeros en modelarlo como una divinidad enigmática y contradictoria. Veían en la supresión de Eros la condición necesaria para la realización efectiva de la cultura. Esta equivalencia fue actualizada por Freud a inicio del siglo $\mathrm{XX}$, quien puntualiza que la humanidad es el resultado del dominio de la pulsión sexual por medio de un acto de sublimación, entendido como la desviación del instinto 


\section{Christian René Rivera Rosero}

sexual hacia fines culturales/civilizatorios. El acto de sublimar es, según Freud, el resultado de suprimir el ello (representación de la naturaleza vinculada al dominio de lo erótico) por parte del superyó, con el que alude al componente disciplinador de la conciencia.

Nuestra cultura descansa totalmente en la coerción de las pulsiones. Todos y cada uno hemos renunciado a una parte de nuestro poderío, a una parte de las tendencias agresivas y vindicativas de nuestra personalidad, y de estas aportaciones, ha nacido la común propiedad cultural de bienes materiales e ideales. [...] Resulta así, que mucha parte de las energías utilizables para la labor cultural tiene su origen en la represión de los elementos perversos de la excitación sexual (Freud, 2008, p.16).

Este debate se halla implícito en Daimón, porque la característica particular del Nuevo Mundo se representa como un lugar de proliferación y exuberancia que se proyecta desde la tierra y se propaga hacia todo lo que participa de ella.

Las quietas flores humedecidas del rocío se entreabren durante la noche para parir la semilla de la araucaria gigantesca. Las tigras corren al alba hacia sus crías llevando el venado exánime, chorreando sangre caliente. Los jacarandáes se incitan con el rozamiento de las ramas más altas movidas por la brisa y estallan las nubes de polvo amarillo, fecundador (los heliotropos, denodados mensajeros del amor, se encargarán de llevar ese polen ardiente hasta los cálices de las ansiosas hembras).

Las monedas caídas, si no son de oro o plata, se disuelven en tres días (...) Una espada que Antón Llamoso dejó clavada para indicar un puesto reparado de lluvia, amaneció puñal: los jugos de esa tierra fuerte la habían decapitado. Era seguro que las balas perdidas terminaban en flor en la primavera siguiente (Posse, 1989, pp. 13-14).

$\mathrm{Al}$ iniciar la lectura de la novela, es evidente que todo se halla regido por ese exceso que Occidente considera peligroso e incompatible con la idea de civilización, porque el espacio en el que se desarrolla la trama no se funda sobre la represión de las fuerzas naturales; todo lo contrario, ese ímpetu se proyecta desde la tierra y se irradia a todo lo que entra en contacto con ella. Lo relevante es que la muerte-vida de los protagonistas está incuestionablemente vinculada a la fertilidad y la exuberancia de entorno, ya que para las culturas precolombinas: la tierra es el principio de absorción y resurrección; el trasunto de la tumba y el vientre. Esta propagación no tarda en mostrar su rostro más profano, debido a que provoca la regeneración de los muertos y su restitución en la historia. De ahí que antes de emprender su nueva empresa, Lope de Aguirre consulte el Tarot y las cartas delaten su condición de redivivo: "Es la carta del renacimiento, del ciclo cumplido, del jubileo. Mírala Señor: este que está parado en la tumba podría ser Lázaro. Es el renacimiento, con un hambre de la vida que solo puede traerse de la huesa (...)" (Posse, 1989, p. 18). 
Este acto de transgresión se presenta en Daimón a manera de revisión histórica, por cuanto Lope de Aguirre pretende alterar, una vez restituido al tiempo histórico, el pasado, estableciendo una nueva jornada que imite la temporalidad de los ciclos naturales, rompiendo de esta manera la temporalidad oficial. Este tiempo profano es anticipado al inicio de la novela a modo de epígrafe: "Siguió viviendo en el Eterno Retorno de lo Mismo, que es una espiral espacio-temporal" (Posse, 1989, p. 10).

Es necesario notar, además, que, bajo la perspectiva de la novela, este Nuevo Mundo ha subvertido la proyección del discurso histórico oficial, deslizando su condición marginal hacia un lugar más céntrico. Por esta razón, la resurrección de Lope de Aguirre y sus marañones posibilita que en los muertos persista una verdad que no ha terminado de decirse, la misma que prolonga una historia particular, anacrónica, desbordada a fuerza de leyendas y obsesiones. Dentro de este marco, la narración recoge otras tradiciones, relatos y cosmovisiones de un tiempo regido por un calendario alterno (precolombino), volviéndola diversa, polifónica e incluyente: "Ahora parecía recordar: ¡Y la rabia por lo que no se tuvo, por lo que no se hizo, por los amores, por las venganzas, por todo lo que hubo bueno o malo! ¡El oro, las mujeres, El Dorado! ¡Yo digo que nada está descubierto! ¿Que nada está concluido!' (Posse, 1989, p. 15).

Tal es la propuesta de distorsión temporal que propone Daimón que sus personajes marchan durante cinco siglos de historia americana. La novela se divide en dos partes. Así, la primera parte, La epopeya del guerrero, inicia once años después de la muerte de Lope de Aguirre, en Barquisimeto; mientras que la segunda, La vida personal, transcurre en los siglos XIX y XX, donde sus personajes atestiguan la llegada de la Ilustración y las primeras tentativas de los movimientos independentistas de las nacientes Repúblicas, el hastío de la modernidad; continúa la marca de Lope y sus "marañones" hasta atestiguar el nacimiento de la insurgencia de latinoamericanos a mediados del siglo XX. Por último, Abel Posse nos regala un guiño narrativo, pues el tiempo de la lectura casi alcanza a rozar el tiempo de la escritura de la novela. Lo que insinúa, como lo ha visto de manera acertada el Dr. Santiago Juan-Navarro, un ciclo eterno de rebeldías e insubordinaciones propagadas, para siempre, por el furioso Daimón de Lope (Navarro, 2005)4.

\section{LO FEMENINO, LO MATRIARCAL Y EL MITO DE LAS AMAZONAS}

La matriz de la sociedad patriarcal occidental la encontraremos en Grecia. Para la cultura helénica el matriarcado suponía el desorden público y el desequilibrio cósmico. Cuenta el sabio latino Varrón que Cécrope, primer rey de Atenas, que poseía una

\footnotetext{
${ }^{4}$ Es ineludible subrayar lo que algunos críticos han sugerido en cuanto al discurso cuestionador de la historiografía hispanoamericana, la influencia que tuvo en los intelectuales latinoamericanos de la década de los 60 el pensamiento y la retórica inspirada en la revolución cubana y los diversos focos de insurrección a lo largo del continente.
} 
naturaleza doble, la parte superior de su cuerpo era humana y su parte inferior reptil, fue esta peculiaridad en la naturaleza de Cécrope lo que le permitió distinguir las leyes que permitieron a la sociedad helénica trascender de la violencia natural a la mansedumbre de la civilidad ${ }^{5}$. Una de esas leyes que se le atribuyen es la institución matrimonial.

En una sociedad matriarcal las prácticas sexuales de la mujer con varios hombres traían como consecuencia engendramientos en los que era casi imposible reconocer a un solo padre. Este tipo de engendramientos difuminaba los lazos de parentesco incurriendo, muchas veces sin saberlo, en prácticas incestuosas. Con el fin de darle consistencia y unidad a la civilización helénica, Cécrope resolvió suprimir la libertad sexual femenina, entregándola en matrimonio a un solo hombre, su esposo. De este modo, al limitar la práctica sexual azarosa y libérrima de la mujer se protegía a la sociedad del desorden y al mismo tiempo se garantizaba una estructura social a base de la línea paterna (Blake, 2001).

Dentro de este marco, el encuentro entre españoles y amazonas en la América daimónica es muy significativo, porque los conquistadores han sido sometidos por el ejército de mujeres al mando de la reina Cuñán y son convertidos en partícipes de una ritualidad pagana. Las amazonas incitan a los "conquistadores" a tomar un baño en las aguas del Lago, luego los visten con batas largas, preparándolos para una suerte de ritual, que terminará en la cópula. Alcanzan así su objetivo de embarazarse. Este hecho es una clara contravención a los principios patriarcales originados en Grecia: "Habéis sido vencidos. Durante diez lunas permaneceréis en estas tierras. Será hasta que yo misma y las princesas hayamos sido fecundadas..." (Posse, 1989, p. 54).

Es necesario notar que la cultura occidental heredó el imaginario mítico de Grecia en relación con la naturaleza fronteriza o trunca de las amazonas. La sociedad griega se centraba en el guerrero varón y adulto y los ritos de transición en la pubertad definían estos roles dentro de la dinámica social. En este sentido, las amazonas eran vistas como seres que habían renunciado a su papel en la sociedad, esta "renuncia" a su condición problematizaba la asignación de roles dentro de la dinámica social, porque eligen ser guerreras, es decir, asumen un rol que no les corresponde. Esto convirtió a las amazonas en seres fronterizos y marginales donde reside el riesgo de desintegración social. Esta subversión del orden parte de la inversión de ciertas polaridades fundamentales dentro de las sociedades de Occidente.

\footnotetext{
${ }^{5}$ Nótese la apariencia con la que la cultura primitiva griega representaba a Cécrope: la parte bestial, es decir, lo que podría entenderse como el Ello freudiano, se halla vinculada con la tierra; mientras que la parte antropomórfica se aleja de los dominios e influencia de las fuerzas naturales, terrestres. En este sentido, es oportuno citar lo que dice Mircea Eliade acerca de lasignificación de la serpiente: "El mismo símbolo central de fecundidad y de regeneración sometidas a la luna y distribuidas por el astro mismo o por formas consustanciales (magna mater, terra mater) explica la presencia de la serpiente en la iconografía o los ritos de las grandes diosas de la fertilidad universal. Las grandes diosas participan tanto del carácter sagrado de la luna como del carácter sagrado de sol, y por el hecho de que esas mismas diosas son al mismo tiempo divinidades funerarias" [...] (2013, p.163).

162 | AlPHA No 53 (Diciembre 2021) PÁGS. 153-167. ISSN 07 16-4254
} 
Esta "incomodidad" es observada de manera oportuna por Terry Seymour al referir que "La sexualidad femenina desenfrenada y los sentimientos eróticos que esta (la mujer) evocan en los hombres de la expedición son las raíces del desorden y la rebelión" (Seymour, 1999, p. 252). La afirmación de Seymour obedece a que las crónicas y relaciones escritas por los españoles, para quienes la figura de Doña Inés de Atienza es enunciada como elemento de desorden dentro de las tropas de Ursúa. Miguel Otero Silva, quien se documentó ampliamente antes de escribir su novela Lope de Aguirre, príncipe de la libertad, refuerza la idea de Seymour cuando asevera que "Lope de Aguirre entendió que tras de todos aquellos rencores y traiciones, tras de aquellas porfías que acababan siempre en sangre y muerte, estaba tu hermosa mano, mi implacable Inés de Atienza" (Otero Silva, 1985, p. 240).

Por lo contrario, en Daimón propone invertir la idea de que el erotismo femenino es la raíz de todo mal, ya que el catolicismo medieval consideraba a la mujer como la encarnación del pecado, la tentación hecha carne. No de otro modo se comprende el sobresalto de los marañones ante el encuentro con las amazonas.

Estoy seguro que ellas no buscan otra guerra que la del amor..., dice el judío Lipzia. "iLa cosa era anexar el pueblo, conocer sus posesiones y evitar esos ritos finales, que dicen...! temía el Escribano. Como temía también el Cura, pensando que el cuerpo de la grey se desencarcelaría (Posse, 1989, p. 51).

Es importante recordar que Bajtin encuentra en la figura femenina una significación ambivalente, porque está ligada a lo corporal, por tanto, vinculada con la tierra, y al mismo tiempo es principio de vida. Esta versatilidad de lo femenino convierte a la mujer, por consiguiente, a la feminidad, en el principio de inversión del cuadro jerárquico (falocrático) de la sociedad occidental.

\section{DAIMÓN Y LA DECONSTRUCCIÓN SOCIAL DE LAS OPOSICIONES COMO REALIDAD NORMADA}

Daimón da cabida a otras formas de deconstrucción a base de la oposición anatómicas sexuales que han dado paso a una polaridad que justifica la división social del trabajo en Occidente.

En este sentido, el sociólogo francés Pierre Bourdieu señala que en el mundo occidental las relaciones sociales de dominación de género se han establecido como resultado de un conflicto entre lo masculino que incorpora una jerarquía orientada hacia el plano vertical (falocrático): es decir, desde Dios (padre), ubicado en el cielo; mientras que lo femenino que se halla siempre al nivel de la tierra, se identifica con el plano horizontal.

Las ideas de Freud en El malestar de la cultura y las de Herbert Marcuse en Eros y Civilización, sugieren que a medida que se reprime la pulsión erótica, esta represión consigue "edificar", "erigir", "levantar" una cultura. Como se aseveró antes, para la cultura 
occidental lo masculino se reconoce por su orientación vertical -fálica- y niega (o rebaja al menos) por oposición el plano horizontal personificado por la diosa de la fertilidad.

Ahora bien, en la América daimónica, es posible apreciar una reestructuración jerárquica fundamentada en la alteración del eje vertical (mundo occidental) para aproximarlo al eje horizontal, de manera que el principio proliferador y femenino de la naturaleza predomine en el Nuevo Mundo. Así pues, al ingresar al territorio de las amazonas, el centro ritual de esta tribu es la laguna Yacihuara o Lago de la Luna, ambas identificables con lo "venusino", lo femenino.

De acuerdo con el sociólogo francés Pierre Bordieu, en el mundo occidental, las relaciones sociales de dominación de género se han establecido como resultado de un conflicto entre lo masculino que incorpora una jerarquía orientada hacia el plano vertical (falocrático): es decir, desde Dios (padre), ubicado en el cielo; mientras que lo femenino que se halla siempre al nivel de la tierra, se identifica con el plano horizontal. ${ }^{6}$

De este modo, la impugnación de la historia en Daimón se revela en una suerte de reorientación del mencionado eje vertical hacia el horizontal, que es mucho más congruente con las prácticas litúrgicas ancestrales que muestran una relación directa entre la fecundidad erótica de las amazonas y la voluptuosa fertilidad presente en territorio americano. Con este propósito, el mundo narrativo de Daimón devela en las amazonas una gran carga simbólica que patentiza la confrontación entre el eje vertical (masculino) y la hegemonía femenina ejercida dentro del territorio americano. Gracias a este predominio de lo femenino es posible hallar un nexo entre el frenesí orgiástico al que son sometidos los conquistadores y la reintegración a la unidad primordial dentro del "gran útero" que acoge la vida y la muerte. Se propicia, también, el sentido del tiempo cíclico de los rituales agrarios de las culturas amerindias. De ahí que el riesgo radique en la transferencia, por medio de los rituales amorosos, al tiempo cíclico agrario, dejando a un lado el devenir temporal de Occidente, alterando el calendario occidental.

Otra forma de polaridad que se ve subvertida en Daimón es la que refiere el sociólogo francés como oposición Interior/Exterior.

$\mathrm{Al}$ establecerse los roles en las sociedades patriarcales, el campo de acción de la mujer se limitó a las cuatro paredes del hogar, a su vez las labores del exterior tenían una connotación masculina: la guerra, la política, etc. Esta disposición de los papeles instituyó la polaridada Interior/Exterior. Las amazonas invierten esta polaridad, poniendo en riesgo el funcionamineto social de la polis. Rechazaban la institución del matrimonio, sus apareaminetos se realizan al azar; para ellas no tiene ninguna importancia reconocer su

\footnotetext{
${ }^{6}$ Esta opinión, además de ser compartida por los pensadores mencionados, es reafirmada por el teórico Ruso Mijaíl Bajtin: "Lo alto y lo bajo poseen allí un sentido completO y de manera rigurosa topográfico. Lo alto es el cielo; lo bajo es la tierra; la tierra es el principio de absorción (la tumba y el vientre), y a la vez de nacimiento y resurrección (el seno materno) (2003, p. 21).
}

164 | Alpha № 53 (Diciembre 2021) PÁGS. 153-167. ISSN 07 16-4254 
prole bajo una línea paterna, conservan las niñas y vemos en Daimón cómo los pocos varones que sobreviven han sido castrados (temor ancestral abordado por el psicoanálisis). Estos sirvientes eunucos se encargan de la casa y del cuidado de los infantes; de este modo se invierten la normatividad de los géneros en relación con su campo de acción, porque son ellas las que ahora se ocupan de las tareas exteriores.

Como se puede apreciar, América se transforma en la matriz erótica donde el componente corporal se vincula con la exuberancia vegetal del entorno y articula el tiempo de vida de los conquistadores al devenir cíclico de las civilizaciones precolombinas. De este modo, en el "resurgimiento" de los conquistadores: "todavía con pesadez de lápida. Como paridos de vuelta" (Posse, 1989, p.14). Es posible percibir una desarticulación de los conceptos espacio-temporales que desafían la conciencia temporal del lector y que constituyen, en lo esencial, una visión paródica de la historia: (Lope) "Se tendió en la arena de la costa con la mirada en lo alto, vagamente agobiado por su antiguo temor: que el Supremo Orden pueda transformarse en puro Caos. Que todo vuelva a la primera página de la Biblia" (Posse, 1989, p. 17).

En síntesis, como se puede apreciar, Daimón articula en su estructura elementos del carnaval bajtiniano, como una forma de escritura que tiene por finalidad descubrir una visión dual del mundo. A lo largo de la novela puede apreciarse la aspiración del narrador de proyectar un discurso desde la periferia, ya que, si el discurso historiográfico es monológico (en términos bajtinianos), entonces es necesario ponerlo en confrontación. Para el efecto, superpone una multiplicidad de voces y perspectivas que se descubren como discursos paralelos; se plantean tiempos y configuraciones alternas a modo de anacronía; mantiene la distancia entre la voz del vencedor y la del vencido que da como resultado una conformación de la verdad diversa que hacen del texto una novela polifónica y, como tal, refleja una realidad multívoca donde la otredad es tomada en cuenta.

De esta manera, Daimón es un texto heterodiscursivo; es decir, residen dentro de él realidades que esperan su turno para manifestarse. Esperan, en definitiva, un detonante y ese detonante es lo que Bajtin llama el tiempo del carnaval. El efecto carnavalesco, en la novela de Posse, interpela a la cultura letrada de la crónica tradicional y permite que unas variedades de versiones alternas se manifiesten como discurso letrado, exhibiendo un mundo de referencias carnavalizadas que desmitifican el discurso histórico oficial.

El elemento erótico en Daimón se engarza con la conducta grotesca del carnaval bajtiniano. Contempla el rebajamiento de lo sublime que halla su representación más fiel en la fertilidad natural y originaria de América. En este sentido, también lo femenino es una figura central al hablar de la inclusión de discursos subalterizados, pues dentro del esquema de valores occidental, lo femenino se muestra como un discurso, por defecto, rebajado, oscurecido. En consecuencia, en Daimón se incorpora un elemento subalterizado que cobra dimensiones críticas de alta relevancia, porque el elemento femenino desafía al mismo tiempo el sistema epistémico occidental. En este sentido, 
Daimón se propone distorsionar las categorías ontológicas de la conciencia histórica institucionalizada. Esta muestra una profunda oposición al calendario eurocéntrico y, al mismo tiempo, propone una desmitificación de la cultura racionalista europea; pues si la historicidad exhibe una orientación lineal en Occidente, el carnaval se aparta de esta concepción, y practica una disposición anacrónica que tienen como finalidad la incorporación del pasado en el presente y, de esta manera, niega toda posibilidad de un discurso histórico oficial.

\section{OBRAS CITADAS}

Aracil, María Beatriz. (2004). Abel Posse: de la crónica al mito de América. Cuadernos de América sin nombre .

Bajtin, Mijaíl (2003). La cultura popular en la Edad Media y en el Renacimiento. Alianza editorial.

Blake Tyrrell, William (2001). Las amazonas. Un estudio de los mitos ateniences. Fondo de Cultura Económica.

Bourdieu, Pierre (2013). La dominación masculina. Anagrama.

Diez Torres, Julián (2018). Los marañones y la polémica de la conquista: Retórica e ideas políticas en la carta de lope de Aguirre a Felipe II. ALPHA: Revista de Artes, Letras y Filosofia, , 1(33), 201-214. http://dx.doi.org/10.32735/S07182201201100033

Eliade, Mircea (2013). Tratado de la historia de las religiones. Bibliotera Era.

Estermann, Josef (2015). Filosofía Andina. Abya Yala.

Freud, Sigmund (2008). La moral sexual cultural y la nerviosidad moderna. En N. A. Fuks, Cien Años de novedad. La moral sexual cultural y la nerviosidad moderna (p. 16). Siglo veintiunoeditores.

Marcuse, Herbert (1969). Eros y Civilización. Seix Barral.

Menton, Seymour (1993). La Nueva Novela Histórica de la Ámérica Latina (19791992). Fondo de Cultura Económica .

Navarro, Santiago Juan (2005). El furioso daimón de Lope de Aguirre: hacia un posmodernismo de resistencia en la narrativa histórica de Abel Posse. Stvdium. Revista de humanidades, (pp.151-162). Recuperado el 2 de 10 de 2013, de file:///C:/Users/User/Downloads/Dialnet-ElFuriosoDaimonDeLopeDeAguirre2049961.pdf

Otero Silva, Miguel (1962). Lope de Aguirre, príncipe de la libertad.

Biblioteca Ayacucho.

Pons, María Cristina (1996). Memorias del olvido. La novela histórica de fines del siglo $X X$. Siglo veintiuno editores.

166 | AlPHA № 53 (DiCIEMBRE 2021) PÁGS. 153-167. ISSN 07 16-4254 
Posse, Abel (1989). Daimón. Plaza y Janés.

Sosnowski, Saúl (2010). El cruce de la historia la Narrativa. En D. P. Yurkieivich, Historia de la cultura literaria en Hispaniamérica (pp. 753-760). Fondo de Cultura Económica.

White, Hayden (2003). El texto histórico como artefacto literario.

Ediciones Paidós 